\title{
Metastatic non-small cell lung cancer: a benchmark for quality end-of-life cancer care?
}

\section{Most patients \\ were referred \\ to palliative \\ care services, \\ but this tended \\ to happen later \\ in the illness}

course

Jennifer Philip PhD, FAChPM, MMed

Peter Hudson PhD, BN(Hons), DipAppSc

Adam Bostanc PhD, MPhil, MSC

Annette Street BEd(Hons), PhD

Dell E Horey

PhD, MMedSc(ClinEpidemiol), $B A p p S c^{2}$

Sanchia Aranda $\mathrm{PhD}, \mathrm{MN}^{3}$

Rachel Zordan PhD, BSc(Psych), BSc(Health)

Bruce D Rumbold $\mathrm{PhD}, \mathrm{MA}, \mathrm{MSC}^{2}$

Gaye Moore PhD, MPD, BN(Hons)

Vijaya Sundararajan $M D, M P H, F A C P$

ISt Vincent's Hospital Melbourne, VIC

2 La Trobe University, Melbourne, VIC

3 Cancer Institute NSW Sydney, NSW.

jennifer.philip@ svhm.org.au

doi: 10.5694/mjal4.00579 ung cancer is one of the most common fatal cancers in the world. In Australia, about 7500 patients die from lung cancer each year, ${ }^{1}$ and the median survival for those with metastatic non-small cell lung cancer (NSCLC) is $4-5$ months. ${ }^{2}$ Despite improvements in survival, attention to symptoms and qualityof-life concerns form the mainstay of treatment for most patients.

Those with advanced lung cancer have a substantial symptom burden. Most patients experience appetite loss, fatigue, cough, dyspnoea and chest pain. ${ }^{3,4}$ In 2010, Temel and colleagues demonstrated that early introduction of palliative care integrated with standard oncological care for this population was associated with improved quality of life, reduced depression and less aggressive care at end of life. ${ }^{5}$ Following this, the American Society of Clinical Oncology released a provisional clinical opinion that patients with metastatic NSCLC "should be offered concurrent palliative care and standard oncologic care at initial diagnosis", while national societies have endorsed timely palliative care referral. ${ }^{6,7}$

The aggressiveness of cancer care near the end of life has been proposed as an indicator of quality of care, and centres around the following criteria: overuse of chemotherapy near death; high rates of emergency department (ED) visits; hospital and intensive care unit stays; and underuse of hospice or palliative care services. ${ }^{8}$

A series of population-based studies of cancer care in the United States and Canada revealed the aggressiveness of care at the end of life had increased. ${ }^{9,10}$ Patients more likely to receive aggressive end-of-life care were young, male and rural based, experienced greater comorbidity burden, and had lung, breast or haematological malignancies. ${ }^{910}$

Given the recommendation for integrated palliative care services for

\section{Abstract}

Objectives: To investigate the quality of end-of-life care for patients with metastatic non-small cell lung cancer (NSCLC).

Design and participants: Retrospective cohort study of patients from first hospitalisation for metastatic disease until death, using hospital, emergency department and death registration data from Victoria, Australia, between 1 July 2003 and 30 June 2010.

Main outcome measures: Emergency department and hospital use; aggressiveness of care including intensive care and chemotherapy in last 30 days; palliative and supportive care provision; and place of death.

Results: Metastatic NSCLC patients underwent limited aggressive treatment such as intensive care $(5 \%)$ and chemotherapy $(<1 \%)$ at the end of life; however, high numbers died in acute hospitals (42\%) and $61 \%$ had a length of stay of greater than 14 days in the last month of life. Although $62 \%$ were referred to palliative care services, this occurred late in the illness. In a logistic regression model adjusted for year of metastasis, age, sex, metastatic site and survival, the odds ratio (OR) of dying in an acute hospital bed compared with death at home or in a hospice unit decreased with receipt of palliative care (OR, 0.25; 95\% Cl, 0.21-0.30) and multimodality supportive care (OR, 0.65; 95\% Cl, 0.56-0.75).

Conclusion: Because early palliative care for patients with metastatic NSCLC is recommended, we propose that this group be considered a benchmark of quality end-of-life care. Future work is required to determine appropriate quality-of-care targets in this and other cancer patient cohorts, with particular focus on the timeliness of palliative care engagement.

patients with metastatic NSCLC, we sought to examine the end-of-life care for this patient group. Using routinely collected hospital discharge, ED and death certificate data for a cohort of patients with metastatic NSCLC, we aimed to examine their patterns of care. These included the aggressiveness of care, ED visits, intensive care use, timing of chemotherapy in relation to death, hospitalisation patterns, and place of death. We also aimed to determine patterns of referral to hospital-based supportive and palliative care services.

\section{Methods}

\section{Setting}

Palliative care services in Victoria, Australia, are organised into three main areas: acute hospital consultancy services; community palliative care services providing care in the patient's residence; and specialist inpatient palliative care units. Our study sought to examine the use of hospital-based palliative care services (ie, the first and third areas above).

\section{Data sources}

Hospital discharge and ED data are compiled by over 300 individual hospitals and maintained by the Victorian Department of Health (VDH). ${ }^{11-13}$ The two datasets contain demographic and clinical information on each episode of patient care; their quality is maintained using an independent audit program. ${ }^{14,15}$ Death certificate data are maintained by the Registry of Births, Deaths and Marriages. ${ }^{13}$

These three datasets undergo stepwise deterministic data linkage at VDH. ${ }^{16}$ Linkage staff assess data quality by a series of internal logic checks and manual review of randomly selected case groups. Notably, these data report on patients who have had contact with the hospital sector only.

\section{Metastatic NSCLC cases}

Metastatic NSCLC cases were extracted based on a combination of three 
sets of codes: lung cancer, small cell morphology (excluded), and metastatic extension (Appendix). The first data point or entry to the study was defined as hospitalisation when both NSCLC and metastases were coded. We included only NSCLC patients who were diagnosed with metastatic disease and died between 1 July 2003 and 30 June 2010.

\section{Outcomes}

Supportive care was defined as consultation by one or more of the following services - social work, physiotherapy, occupational therapy, psychology or speech pathology - using Australian Classification of Health Interventions codes. ${ }^{17}$ Palliative care was defined as consultation with a hospital-based palliative care service.

Site of death was based on a combination of hospital and death certificate data and classified into three mutually exclusive groups: outside hospital; inpatient hospice or palliative care bed; and acute care hospital bed.

Aggressiveness of care (adopted from Earle and colleagues ${ }^{8}$ and using available dataset information) was defined by the following parameters in the last 30 days of life: more than one ED presentation; more than one hospital admission; length of stay more than 14 days; intensive care unit admission; and inpatient chemotherapy administration (including same-day admissions) within 14 days of death.

\section{Statistical analysis}

The illness course was divided into three distinct time periods based on key admissions: hospitalisation for first metastasis; interval between metastasis and just before final admission (for those who died in hospital) or death (for those who died outside hospital); and death admission for those who died in hospital (Box 1). The care was described at these time intervals using medians and interquartile ranges for continuous factors, and frequencies and proportions for categorical variables. A logistic regression model was fitted for the question: what factors predict the

\section{Schema of time intervals as basis for analysis}

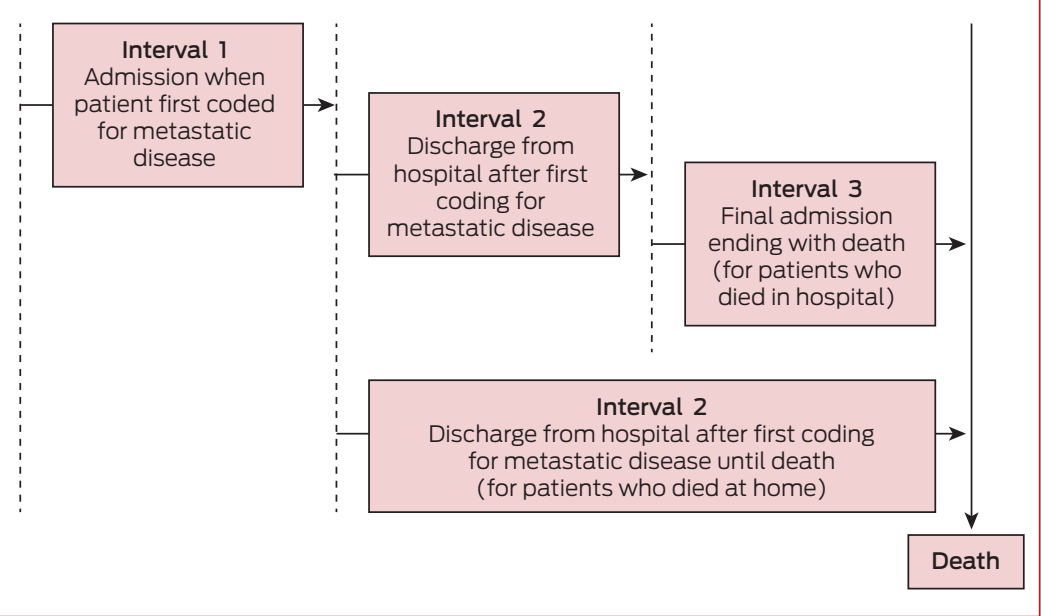

likelihood of death in an acute hospital bed? Stata version 13 (StataCorp) was used for all statistical analyses.

\section{Ethics approval}

This study was approved by the Monash University human research ethics committee.

\section{Results}

There were 6041 eligible NSCLC cases diagnosed with a first metastasis in the period of interest. Eighty per cent were aged $\geqslant 60$ years and $63 \%$ were male (Box 2). At the first hospitalisation for metastatic disease, sites of metastases were: bone, 31\%; lymph nodes, 36\%; lung, $26 \%$; brain, $19 \%$; and $27 \%$ had more than one metastatic site.

\section{Survival}

Median survival after hospitalisation with first metastasis (ie, at point of entry into cohort) was 116 days, with $75 \%$ of patients (4551) surviving at least 43 days and 25\% (1536) over 9 months (range 0-2324 days). This short median survival reflects our sampling frame, which included only those patients who died. Twelve per cent of patients (728) died during the first metastasis admission.

\section{Place of death}

Sixteen per cent of patients died outside of hospital, $42 \%$ in a palliative care unit, and $42 \%$ in an acute hospital bed (Box 2).

\section{Patterns of ED and hospital use from diagnosis to death}

Thirty-five per cent of patients (2104) were admitted through the ED at time of hospitalisation when metastatic disease was first coded. The proportion of patients receiving ED care was $58 \%$ for those who died during the first metastasis admission, and $42 \%$ for those who died in hospital after surviving initial admission (Box 3).

The proportion of patients receiving care in the private system reduced slightly over their cancer care, from $35 \%$ at first metastasis, to $28 \%$ at time of death.

The duration of the first admission where metastatic disease was diagnosed was a median of 43 days for those who died during this admission, compared with 6 days for those who survived the admission. Overall, patients spent a median of 38 days in hospital from first admission of metastatic disease until death.

A third of patients (1998) underwent a lung procedure (including pleuridesis, biopsy, bronchial stenting) during the admission when metastatic disease was first diagnosed, reducing to $6 \%$ during their death admission (Box 3).

\section{Supportive and palliative care from diagnosis to death}

Overall, $62 \%$ of patients were referred to palliative care (Box 2). In general, receipt of supportive care $(96 \%)$ and palliative care $(78 \%)$ were high for the 728 patients dying during the first metastasis admission. Sixty per cent 


\begin{tabular}{|c|c|}
\hline Characteristic & No. of patients \\
\hline \multicolumn{2}{|l|}{$\overline{\text { Age }}$} \\
\hline$<40$ years & $39(1 \%)$ \\
\hline $40-59$ years & $1167(19 \%)$ \\
\hline$\geqslant 60$ years & $4835(80 \%)$ \\
\hline Male & 3815 (63\%) \\
\hline Australian born & $3656(61 \%)$ \\
\hline English as primary language & $4328(72 \%)$ \\
\hline Married & $3869(64 \%)$ \\
\hline Rural residence & 2058 (34\%) \\
\hline \multicolumn{2}{|l|}{ Histology } \\
\hline Adenocarcinoma & $2081(34 \%)$ \\
\hline Large cell carcinoma & $433(7 \%)$ \\
\hline Non-small cell, not further classified & $1655(27 \%)$ \\
\hline Squamous cell carcinoma & $877(15 \%)$ \\
\hline Bronchoalveolar carcinoma & $33(1 \%)$ \\
\hline No histology & $1181(20 \%)$ \\
\hline \multicolumn{2}{|l|}{ Total number of histological types } \\
\hline 0 & $1181(20 \%)$ \\
\hline 1 & $4557(75 \%)$ \\
\hline$\geqslant 2$ & $303(5 \%)$ \\
\hline \multicolumn{2}{|l|}{ Metastatic site at time of diagnosis } \\
\hline Bone & $1890(31 \%)$ \\
\hline Brain & $1156(19 \%)$ \\
\hline Lung & $1565(26 \%)$ \\
\hline Lymph nodes & $2157(36 \%)$ \\
\hline Other & $378(6 \%)$ \\
\hline Referral to hospital-based palliative care services & $3724(62 \%)$ \\
\hline \multicolumn{2}{|l|}{ Place of death } \\
\hline Acute hospital bed & $2547(42 \%)$ \\
\hline Hospice or palliative care bed & $2532(42 \%)$ \\
\hline Out of hospital & $962(16 \%)$ \\
\hline
\end{tabular}

were transferred to a hospice bed during this admission.

Of the remaining 5313 patients who survived the first metastasis admission, $10 \%$ were referred to hospitalbased palliative care by time of discharge (Box 3). A further $22 \%$ were first referred to hospital-based palliative care in the interval between metastasis and death (or death admission for those dying in hospital), and $27 \%$ were referred for the first time when they returned to hospital to die.

\section{Aggressiveness of care}

In the last 30 days of life, $18 \%$ of 5313 patients surviving beyond the first metastasis admission had more than one hospital admission, and 5\% had intensive care treatment. However, aggressive care. with a greater likelihood of death at home or in a palliative care unit. Notably, those surviving at least 270 days after their metastasis admission were less likely to die in an acute bed compared with those surviving less than 90 days. There was no change in the likelihood of dying in an acute bed over the time of the study.

\section{Discussion}

Our study provides an overview of care for patients with metastatic NSCLC in Victoria, Australia. It found that $42 \%$ of patients who die due to NSCLC can expect to die in an acute hospital and $42 \%$ in a hospice setting, having spent a median of 38 days in hospital after the onset of metastatic disease.

Although the patients did not generally receive aggressive care in the form of intensive care unit treatment or chemotherapy in the last 14 days of life, other parameters of aggressive care - notably, death in acute hospital and ED visits - were common. Perhaps the most important finding is the low numbers of patients discharged from hospital following the diagnosis of metastatic disease who were referred to hospital palliative care services during the first admission for metastasis $(10 \%)$. This is a group of patients with poor prognostic disease, who are not being identified as requiring palliative care services. pital, and less than $1 \%$ had chemotherapy in the last 14 days of life (Box 4). Thirty-three per cent (2010) were not flagged by any indicator of

\section{Factors associated with place of death}

For patients who survived the first admission with metastatic disease, $42 \%$ died in an acute hospital bed (Box 2). Factors independently associated with increased likelihood of death in an acute bed included treatment in the private system and a rural place of residence (Box 5). Meanwhile, receipt of palliative care at any point, receipt of two or more modalities of supportive care, and English as the primary language were associated
We propose that the care of people with metastatic NSCLC is a reasonable benchmark of the quality of end-of-life care or, more broadly, palliative care, for those with eventually fatal oncological disease. This is because metastatic NSCLC is associ4 months in our study) and a high symptom burden, ${ }^{2-4}$ has high-quality evidence of benefits from palliative care; ${ }^{5}$ and palliative care has been recommended as part of standard practice. ${ }^{6,18}$ Such key unambiguous reasons for routinely involving palliative care for patients with metastatic NSCLC may provide the ideal model for assessing the quality of end-of-life care provision. ated with a poor prognosis (less than 
3 Patterns of hospital use, and supportive and palliative care $(n=6041) *$

\begin{tabular}{|c|c|c|c|c|}
\hline \multirow[b]{2}{*}{ Variable } & \multicolumn{2}{|c|}{ Interval 1: first metastasis admission } & \multirow[b]{2}{*}{$\begin{array}{l}\text { Interval 2: between } \\
\text { metastasis and death }\end{array}$} & \multirow[b]{2}{*}{$\begin{array}{l}\text { Interval 3: death in hospital }{ }^{\ddagger} \text { after } \\
\text { surviving metastasis admission }\end{array}$} \\
\hline & $\begin{array}{l}\text { Died during } \\
\text { admission }\end{array}$ & $\begin{array}{l}\text { Alive after } \\
\text { admission }\end{array}$ & & \\
\hline Total at beginning of each interval ${ }^{\S}$ & 728 & 5313 & 5313 & 4440 \\
\hline Median days during each interval (range) & $43(30-254)$ & $6(1-181)$ & $123(0-2304)$ & $10(1-271)$ \\
\hline Any hospitalisation & $728(100 \%)$ & $5313(100 \%)$ & $4360(82 \%)$ & $4440(100 \%)$ \\
\hline Median bed days per person (range) & $43(30-254)$ & $6(1-181)$ & $20(1-515)$ & $7(1-195)$ \\
\hline Any ED visit & $422(58 \%)$ & $1682(32 \%)$ & $2707(51 \%)$ & $1860(42 \%)$ \\
\hline Median ED visits per person (range) & 1 & 1 & $2(1-3)$ & 1 \\
\hline Median hours spent in ED per person (range) & $8(0-54)$ & $8(0-49)$ & $12(0-145)$ & $7(0-180)$ \\
\hline Intensive care unit admission & $72(10 \%)$ & $656(12 \%)$ & $288(5 \%)$ & $215(5 \%)$ \\
\hline Lung procedures & $228(31 \%)$ & $1770(33 \%)$ & $897(17 \%)$ & $257(6 \%)$ \\
\hline Chemotherapy as inpatient & $11(2 \%)$ & $221(4 \%)$ & $417(8 \%)$ & $18(<1 \%)$ \\
\hline Radiotherapy as inpatient & $78(11 \%)$ & $226(4 \%)$ & $235(4 \%)$ & $127(3 \%)$ \\
\hline \multicolumn{5}{|l|}{ No. of supportive care modalities } \\
\hline 0 & $31(4 \%)$ & $2616(49 \%)$ & $1039(20 \%)$ & $1760(40 \%)$ \\
\hline 1 & $72(10 \%)$ & $975(18 \%)$ & $935(18 \%)$ & $911(21 \%)$ \\
\hline$\geqslant 2$ & $625(86 \%)$ & $1722(32 \%)$ & $2388(45 \%)$ & $1724(39 \%)$ \\
\hline First palliative care & $569(78 \%)$ & $531(10 \%)$ & $1176(22 \%)$ & $1448(32 \%)^{\natural}$ \\
\hline
\end{tabular}

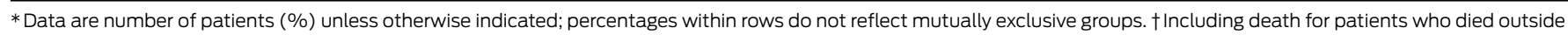

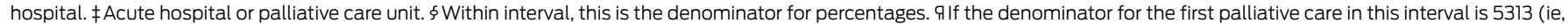
patients who survived the diagnostic metastasis admission), the proportion is $27 \%$.

In this context, our study shows that for metastatic NSCLC patients, where the case for palliative care is strong, gaps remain in service provision. For example, just $18 \%$ of patients overall received hospital-based palliative care services at the first sign of metastatic disease, including those who died during that admission; referral was far less frequent among those discharged from hospital. While this proportion increased to $62 \%$ overall, about a quarter of these patients first received palliative care services in the readmission that resulted in their death.

Palliative care referrals, when they do occur, appear often to be late in the illness. Poulose and colleagues highlighted the timing of referral

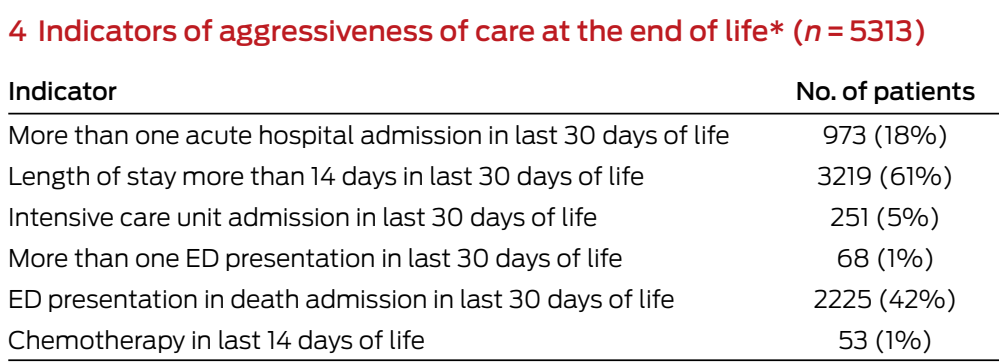

ED = emergency department. * Includes death admission for patients who died in hospital. is a marker of poor-quality care. ${ }^{8}$ to palliative care as important, suggesting that referral at least 30 days before death is associated with a greater chance of dying at home or in hospice, ${ }^{19}$ the preferred options expressed by most surveyed patients. ${ }^{20-22}$ Similarly, Earle and colleagues suggested that hospice admission 3 days or less before death

In our study, referral occurred very late, at the time of death admission, for about a quarter of all patients surviving the initial admission with metastasis. This may not represent the first contact with palliative care services for all patients, as they may previously have been involved with community care, but it is likely to be the first contact for at least a

. may be the most pertinent quality indicator(s). In our study, $62 \%$ of patients were engaged with hospitalbased palliative care services overall. This figure is high, and may be even higher since community-based care was not captured. Nevertheless, only $18 \%$ accessed palliative care during the admission when metastatic disease was diagnosed, potentially the most appropriate time to discuss the 


\begin{tabular}{|c|c|c|}
\hline Death in acute hospital bed & Odds ratio $(95 \% \mathrm{Cl})$ & $P$ \\
\hline \multicolumn{3}{|l|}{ First receipt of palliative care } \\
\hline No palliative care & 1.00 & \\
\hline $\begin{array}{l}\text { Within } 30 \text { days, during metastasis } \\
\text { admission }\end{array}$ & $0.27(0.22-0.33)$ & $<0.001$ \\
\hline $\begin{array}{l}\geqslant 30 \text { days after metastasis and before death } \\
\text { admission }\end{array}$ & $0.25(0.21-0.30)$ & $<0.001$ \\
\hline Death admission & $0.22(0.19-0.25)$ & $<0.001$ \\
\hline \multicolumn{3}{|l|}{ Sex } \\
\hline Male & 1.00 & \\
\hline Female & $0.97(0.85-1.10)$ & ns \\
\hline \multicolumn{3}{|l|}{ Age, years } \\
\hline$<40$ & 1.00 & \\
\hline $40-59$ & $0.66(0.33-1.31)$ & ns \\
\hline$\geqslant 60$ & $0.59(0.30-1.16)$ & ns \\
\hline Private hospital & $1.25(1.10-1.42)$ & $<0.001$ \\
\hline English speaking & $0.82(0.72-0.94)$ & 0.01 \\
\hline Married & $1.06(0.97-1.16)$ & ns \\
\hline Rural & $1.62(1.42-1.84)$ & $<0.001$ \\
\hline \multicolumn{3}{|l|}{ Metastases } \\
\hline Bone & $0.96(0.83-1.11)$ & ns \\
\hline Brain & $0.88(0.74-1.05)$ & ns \\
\hline Liver & $0.97(0.82-1.15)$ & ns \\
\hline Lung & $1.16(0.99-1.35)$ & ns \\
\hline Lymph nodes & $1.21(1.04-1.39)$ & 0.011 \\
\hline Other & $0.95(0.72-1.24)$ & ns \\
\hline \multicolumn{3}{|l|}{ Total number of supportive care modalities } \\
\hline 0 & 1.00 & \\
\hline 1 & $0.88(0.73-1.07)$ & ns \\
\hline 2 & $0.65(0.56-0.75)$ & $<0.001$ \\
\hline \multicolumn{3}{|l|}{ Year of metastasis } \\
\hline 2003 & 1.00 & \\
\hline 2004 & $1.09(0.83-1.42)$ & ns \\
\hline 2005 & $1.15(0.88-1.51)$ & ns \\
\hline 2006 & $1.08(0.83-1.42)$ & ns \\
\hline 2007 & $1.27(0.97-1.67)$ & ns \\
\hline 2008 & $1.07(0.82-1.41)$ & ns \\
\hline 2009 & $1.15(0.86-1.53)$ & ns \\
\hline 2010 & $1.20(0.75-1.91)$ & ns \\
\hline \multicolumn{3}{|l|}{ Days lived } \\
\hline$<90$ & 1.00 & \\
\hline $90-179$ & $0.89(0.75-1.05)$ & ns \\
\hline $180-269$ & $0.88(0.73-1.07)$ & ns \\
\hline $270-364$ & $0.74(0.58-0.93)$ & 0.012 \\
\hline$\geqslant 365$ & $0.77(0.63-0.93)$ & 0.006 \\
\hline
\end{tabular}

ns= not significant.

benefits of palliative care for this patient group. What level of palliative care should be considered the preferred standard of quality endof-life care for metastatic NSCLC patients, and when should referral occur? Is the current proportion of $18 \%$ receiving palliative care at first admission with metastatic disease sufficient, or would $50 \%$ or even $90 \%$ of patients indicate better-quality care, in light of evidence that referral to palliative care at this time may prolong survival? ${ }^{5}$ Further, how should quality be judged in other diagnostic cohorts where the associated factors are ambiguous, such as when prognosis is longer?

Our study had several limitations. The analysis relied on routinely collected hospital data, so care events that took place outside hospital were not collected. This means that patients diagnosed with a metastasis as outpatients and never admitted were not part of our analysis. Similarly, community-based palliative care provision was not available in our dataset, and therefore receipt of palliative care is likely to be higher than we have reported. In Western Australia, this has been found to represent up to $24 \%$ of cancer patients. ${ }^{25}$ While local care patterns are likely to be influential, this community-only group may also be significant in Victoria. Oral chemotherapy regimens not requiring intravenous drug administration would not have been captured. Finally, our cohort included patients who were diagnosed and died within the follow-up period, which meant that particularly long survivors were not included. Nevertheless, our approach enabled us to document care during the whole illness period for those included, which was consistent with our focus on care at the end-of-life.

In conclusion, we sought to establish the current patterns of care and use of hospital palliative care for patients with metastatic NSCLC in Victoria. In this group, who we propose as a benchmark of quality end-of-life care, there was limited use of aggressive treatment measures such as intensive care and chemotherapy at end of life, although high numbers of people died in acute hospitals following a substantial length of stay. Most patients were referred to palliative care services, but this tended to happen later in the illness course. Future work is required to determine appropriate targets for quality endof-life care in this and other cancer patient cohorts, with particular focus on timely palliative care engagement.

Acknowledgements: Our study was supported by a peer-reviewed grant from the Victorian Cancer Agency.

Competing interests: No relevant disclosures.

Received 18 Apr 2014, accepted 18 Sep 2014 . 
1 Australian Institute of Health and Welfare. Lung cancer. Australian Cancer Incidence and Mortality (ACIM) books. http://www.aihw.gov.au/acim-books (accessed Sep 2014).

2 Cetin K, Ettinger DS, Hei YJ, O'Malley CD. Survival by histologic subtype in stage IV nonsmall cell lung cancer based on data from the Surveillance, Epidemiology and End Results Program. Clin Epidemiol 2011; 3: 139-148.

3 Lutz S, Norrell R, Bertucio C, et al. Symptom frequency and severity in patients with metastatic or locally recurrent lung cancer: a prospective study using the Lung Cancer Symptom Scale in a community hospital. J Palliat Med 2001; 4: 157-165.

4 Cooley ME, Short TH, Moriarty HJ. Symptom prevalence, distress, and change over time in adults receiving treatment for lung cancer. Psychooncology 2003; 12: 694-708.

5 Temel JS, Greer JA, Muzikansky A, et al. Early palliative care for patients with metastatic non-small-cell lung cancer. N Engl J Med 2010; 363: 733-742.

6 Smith TJ, Temin S, Alesi ER, et al. American Society of Clinical Oncology provisional clinical opinion: the integration of palliative care into standard oncology care. J Clin Oncol 2012; 30: 880-887.

7 Australian and New Zealand Society of Palliative Medicine. Timely referral to specialist palliative care services for patients with progressive solid tumours. Position statement. Canberra: ANZSPM, 2014. http://www.anzspm. org.au/c/anzspm?a=sendfile\&ft=p\& fid $=1404180739 \&$ sid $=$ (accessed Sep 2014).

8 Earle CC, Landrum MM, Souza JM, et al. Aggressiveness of cancer care near the end of life: is it a quality-of-care issue? J Clin Oncol 2008; 26: 3860-3866.

9 Ho TH, Barbera L, Saskin R, et al. Trends in the aggressiveness of end-of-life cancer care in the universal health care system of Ontario, Canada. J Clin Oncol 2011; 29: 1587-1591.

10 Warren JL, Barbera L, Bremner KE, et al. End-of-life care for lung cancer patients in the United States and Ontario. J Natl Cancer Inst 2011; 103: 853-862.

11 Department of Health, Victoria. Victorian Emergency Minimum Dataset (VEMD). http://www.health.vic.gov. au/hdss/vemd/index.htm (accessed Mar 2012).

12 Department of Health, Victoria. Victorian Admitted Episodes Dataset (VAED). http://www.health.vic.gov.au/ hdss/vaed/index.htm (accessed Mar 2012).

13 Department of Justice, Victoria. Victorian Births Deaths Marriages. www.bdm.vic.gov.au (accessed Mar 2012).

14 Henderson T, Shepheard J, Sundararajan V. Quality of diagnosis and procedure coding in ICD-10 administrative data. Med Care 2006; 44: 1011-1019.

15 Department of Health, Victoria. Office of Data Integrity. http://www.health. vic.gov.au/divisions/data-integrity.htm (accessed Feb 2015).

16 Department of Health, Victoria. Victorian data linkages. http://www. health.vic.gov.au/vdl (accessed Mar 2012).

17 Australian Institute Health Welfare. Australian Classification of Health Interventions (ACHI). 8th ed. Wollongong: Australian Health Services
Research Institute, University of Wollongong, 2013.

18 Detterbeck FC, Lewis SZ, Diekemper R, et al. Executive Summary: Diagnosis and management of lung cancer, 3rd ed: American College of Chest Physicians evidence-based clinical practice guidelines. Chest 2013; 143 (5 Suppl): 7S-37S.

19 Poulose JV, Do YK, Neo PS. Association between referral-to-death interval and location of death of patients referred to a hospital-based specialist palliative care service. J Pain Symptom Manage 2013; 46: 173-181.

20 Stajduhar KI, Allan DE, Cohen SR, Heyland DK. Preference for location of death of seriously ill hospitalized patients: perspectives from Canadian patients and their family caregivers. Palliat Med 2008; 22: 85-88.

21 Brazil K, Howell D, Bedard M, et al. Preferences for place of care and place of death among informal caregivers of the terminally ill. Palliat Med 2005; 19 : 492-499.

22 Tang ST. When death is imminent: where terminally ill patients with cancer prefer to die and why. Cancer Nurs 2003; 26: 245-251.

23 McNamara B, Rosenwax L. Factors affecting place of death in Western Australia. Health Place 2007; 13: 356-367.

24 Sundararajan V, Bohensky MA, Moore G, et al. Mapping the patterns of care, the receipt of palliative care and the site of death for patients with malignant glioma. J Neurooncol 2014; 116: 119-126.

25 Rosenwax LK, McNamara BA. Who receives specialist palliative care in Western Australia - and who misses out. Palliat Med 2006; 20: 439-445. 